\title{
Academia e serviços de saúde na consolidação do internato de enfermagem
}

\section{Academy and health services in the consolidation of boarding school of nursing}

\author{
Simone Domingues Garcia ${ }^{1}$; Marli Terezinha Oliveira Vannuchi²; Carolina \\ Zandonadi Ciciliato ${ }^{3}$; Beatriz Silva Ignotti ${ }^{4}$
}

\begin{abstract}
Resumo
$\bar{O}$ estudo objetivou analisar a percepção de docentes e enfermeiros sobre a estruturação do internato de enfermagem de uma universidade pública. Utilizou-se a metodologia qualitativa. A coleta de dados foi de março a agosto de 2012 por meio da ferramenta eletrônica Google Docs, com o uso de questões abertas e fechadas. Os 27 participantes do estudo foram enfermeiros docentes e dos serviços utilizados como campo de estágio do internato de enfermagem. A análise dos dados possibilitou o estabelecimento de duas categorias: Parceria entre academia e serviços de saúde: da construção a realização do internato e avaliação do internato de enfermagem: da estruturação a efetividade. Os resultados demonstraram que a base da consolidação do internato de enfermagem é a parceria da academia com as instituições de saúde e o fortalecimento de propostas pedagógicas inovadoras, além da sistemática de avaliações participativas entre os envolvidos pautadas na realidade exigida do mercado de trabalho.
\end{abstract}

Palavras-chave: Educação em enfermagem. Enfermagem. Apoio institucional.

\begin{abstract}
The study aimed to analyze the perception of teachers and nurses on the structure of the nursing internship at a public university of Paraná. We used a qualitative methodology to the collection in the period from March to August 2012. We used the electronic tool Google Docs, which enables the use of open and closed questions as well as data storage. The 27 study participants were nurse teachers and from the services used as training field of nursing internship. Data analysis enabled the establishment of two categories: Partnership between academia and health services: the construction of the completion of the internship and nursing boarding rating: structuring effectiveness. The results showed that the basis of consolidation of the nursing internship is the partnership of academia with health institutions and the strengthening of innovative educational proposals, as the systematic participatory assessments among stakeholders guided by the required reality of the labor market.
\end{abstract}

Keywords: Nursing Education. Nursing. Institutional support.

\footnotetext{
${ }^{1}$ Enfermeira, mestre em enfermagem pela Universidade Estadual de Londrina, com especialização modalidade residência em Gerência dos Serviços de Enfermagem.

${ }^{2}$ Enfermeira, Doutora em saúde pública pela Universidade de São Paulo, docente do departamento de enfermagem da Universidade Estadual de Londrina.

${ }^{3}$ Enfermeira, graduada pela Universidade Estadual de Londrina.

${ }^{4}$ Enfermeira, graduada pela Universidade Estadual de Londrina.
} 


\section{Introdução}

A formação do enfermeiro generalista, capaz de atuar na complexa realidade da atenção à saúde, tem inquietado e mobilizado diversos profissionais da área, proporcionando novos questionamentos sobre os planos curriculares dos cursos de graduação em enfermagem e as competências e habilidades essenciais necessárias para a formação de novos enfermeiros (COLENCI; BERTI, 2012).

Para garantir a efetividade dessa formação, além da estruturação curricular adequada, o enfermeiro deve se adaptar rapidamente às mudanças que ocorrem ao iniciar o exercício profissional. A formação depara-se com desafios e incongruências entre o conhecimento adquirido e a prática profissional, que traz uma realidade por vezes divergente da teoria dos livros (MATTOSINHO et al., 2010).

Assim, os serviços de saúde atuam como peças fundamentais na formação de novos profissionais ao serem utilizados como campos de práticas e de estágios curriculares, caracterizando-os como disparadores da realidade da prática dos enfermeiros. É perceptível que ainda há um descompasso entre a formação no ensino superior e as expectativas no campo de trabalho, tornando-se um fator estressante aos novos profissionais (MATTOSINHO et al., 2010).

A integração entre a academia, serviços de saúde e a comunidade é fundamental para oferecer uma formação na lógica do Sistema Único de Saúde (SUS) em seus diversos níveis de atenção e esferas governamentais, contando inclusive com a participação social nesse processo (DEMARZO et al., 2009).

Dentre as atividades desenvolvidas na formação do enfermeiro tem-se o estágio curricular, momento importante de ação do SUS ao assumir o papel de interlocutor, orientando a formulação de projetos políticos pedagógicos e a função de campo de prática (estágio/aprendizagem) (COSTA; MIRANDA, 2009).
Os estágios curriculares devem proporcionar aos alunos meios de situar, observar e aplicar criteriosa e reflexivamente, princípios e referenciais teórico-práticos assimilados ao longo da graduação, sendo imprescindível o inter-relacionamento multidisciplinar entre teoria e prática, sem perder de vista a realidade na qual está inserido, que são os serviços de saúde (COSTA; GERMANO, 2007).

Constata-se que o estágio curricular obrigatório, denominado de internato de enfermagem em algumas instituições, é considerado um momento de suma importância no processo de formação profissional e pessoal do aluno de enfermagem, e a figura do enfermeiro das unidades de saúde, campo de atuação do interno, juntamente com o apoio das instituições de saúde tem significativa influência na gestão prática e pedagógica do internato (VANNUCHI et al., 2014).

Com isso, o enfermeiro em sua práxis diária deve ser considerado como uma das principais peças do projeto do SUS, com destaque para sua atuação no campo das práticas, da docência e da pesquisa. Porém é primordial que o mesmo reconheça seu importante papel, com as devidas responsabilidade e potencialidade pedagógica do seu trabalho (DAVID; ACIOLI, 2010).

Como problema de pesquisa, enfoca-se a dimensão educativa no trabalho de enfermagem, com a interação entre a docência e os enfermeiros dos serviços reconhecendo-se como educadores na formação de novos profissionais. Compreende-se que a ação educativa possui predisposição a ser vista como uma ação técnica componente ou adicional ao conjunto de práticas profissionais, em lugar de uma dimensão inerente à prática profissional, fortalecendo assim a necessidade de novos estudos que abordem o tema (DAVID; ACIOLI, 2010).

É preciso reconhecer a dimensão educativa como práxis e atitude educativa, responsabilidade inerente ao processo de trabalho de enfermagem. Trata-se de reconhecer o potencial pedagógico do trabalho de enfermagem como um todo. Nesta 
perspectiva, retoma-se uma concepção integradora a respeito do trabalho como prática social (DAVID; ACIOLI, 2010).

A busca de estudos referentes à participação de docentes em parceria com os enfermeiros de serviços de saúde na condução do internato de enfermagem mostrou escassez de referências, dado a importância do tema e a relevância de fortalecer ainda mais essa parceria entre academia e serviços de saúde. Assim, o objetivo desse estudo foi analisar as percepções de docentes e enfermeiros de serviço em relação à estruturação de um internato de enfermagem.

O estudo faz parte de um projeto de pesquisa intitulado "Parceria entre docentes e enfermeiros de campo na condução do internato de enfermagem" cujo objetivo é a produção de pesquisas que potencializam os profissionais envolvidos em todo o processo de desenvolvimento do internato de enfermagem.

\section{Método}

Trata-se de um estudo descritivo e exploratório, com a utilização da metodologia qualitativa. A pesquisa qualitativa está relacionada aos significados que as pessoas atribuem às suas experiências e à compreensão do mundo social. Representa uma interpretação dos fenômenos sociais (interações, comportamentos, etc.) em termos dos sentidos que as pessoas lhes atribuem (POPE; MAYS, 2009).

A pesquisa qualitativa se preocupa com o nível de realidade que não pode ser quantificado, ou seja, ela trabalha com o universo de significados, motivos, aspirações, crenças, valores e atitudes. O pesquisador está preocupado com as marcas discursivas contidas no relato com o qual o indivíduo busca se apropriar de suas experiências (INOCENTE; SCORSOLINICOMIN; MATIAS, 2009).

O local do estudo foi o Centro de Ciências da Saúde, um dos centros de estudos pertencentes à Universidade Estadual de Londrina (UEL), onde se localiza o curso de enfermagem da instituição.
Os participantes do estudo foram enfermeiros assistenciais e enfermeiros docentes compartes do internato de enfermagem da UEL. Para a busca dos participantes contou-se com o auxílio da Coordenação do Colegiado do Curso de Enfermagem da UEL, que disponibilizou os nomes dos docentes e enfermeiros envolvidos na prática formativa. Como critério de inclusão tanto os enfermeiros quando os docentes deveriam estar envolvidos há pelo menos dois anos no estágio, o que possibilita o envolvimento dos participantes desde o planejamento do internato de enfermagem até a sua realização.

Após selecionar os profissionais realizou-se novo contato com o Colegiado do curso para obtenção do endereço eletrônico (e-mail), forma selecionada para a realização do estudo.

Para a coleta e armazenamento dos dados optouse pelo uso da ferramenta Google Docs, que é um instrumento on-line desenvolvida pelo Google, podendo ser utilizada em qualquer browser. As aplicações desenvolvidas no Google Docs são constituídas por um processador de texto, um editor de apresentações e um editor de folhas de cálculo. Os aspectos mais interessantes destas aplicações são a sua fácil usabilidade, e a possibilidade de editar um mesmo documento por mais de um utilizador. Tendo em conta essas funcionalidades, a ferramenta Google Docs pode ser utilizada por diferentes atores, favorecendo o processo de ensino-aprendizagem através da escrita colaborativa (BARROSO; COUTINHO, 2009).

As perguntas do questionário foram embasadas nas habilidades e desempenhos contidos no caderno do módulo do internato de enfermagem por meio de questões abertas e fechadas contemplando: estruturação dos campos do internato, relacionamento interpessoal, estruturação do material de apoio dos internos, planejamento das atividades do internato, entre outros.

Como exemplo das questões: Você considera que os campos de estágios estão em condições adequadas para o desenvolvimento dos internos? 
Em sua opinião quem deve participar da construção do plano de atividades a serem desenvolvidas pelos internos? Qual a estratégia utilizada por docentes e enfermeiros de campo para auxiliarem os estudantes com dificuldades de aprendizagem?

Utilizou-se análise de conteúdo, que consiste em um conjunto de técnicas de análise das comunicações por meio de procedimentos sistemáticos e objetivos de descrição do conteúdo das mensagens, indicadores (quantitativos ou não). A técnica oportuniza a conclusão de conhecimentos relativos e recepção destas mensagens, levando a construção de categorias por meio de depoimentos (BARDIN, 2009).

Os enfermeiros docentes e enfermeiros assistenciais não foram diferenciados nas falas, ao considerar que mesmo ocupando espaços diferentes na formação dos alunos, ambos são de fundamental importância, com isso optou-se por ouvi-los e valorizá-los da mesma forma na construção do estudo. As falas foram apresentadas conforme o uso das questões nas categorias, preservando qualquer tipo de identificação dos participantes.

O período de envio do e-mail com as informações do questionário eletrônico correspondeu a seis meses, sendo de março a agosto de 2012 com um intervalo de dois meses entre cada envio, totalizando três envios. $\mathrm{O}$ envio do e-mail foi realizado mais de uma vez para obtenção de um maior número de participantes.

A pesquisa possui aprovação do Comitê de Ética em Pesquisa CAAE: 0168.0.268.000-11.

\section{Resultados e Discussão}

O questionário eletrônico foi enviado para 65 enfermeiros, sendo 31 docentes e 34 enfermeiros de campo. Dos e-mails enviados obtiveram-se respostas de 27 (42\%). Considerou-se que o baixo número de questionários retornados aconteceu devido ao uso do questionário eletrônico para a coleta de dados, ferramenta considerada nova o que pode causar dúvidas nos participantes que desconhecem a segurança oferecida em sua utilização. Há também a limitação de que nem todos os sujeitos de pesquisa utilizam a informática como instrumento de trabalho diário.

Dos 27 enfermeiros que participaram, 71\% graduaram-se na UEL e possuem mais de 15 anos de atuação profissional. Os participantes integram o internato há mais de dois anos e quatro desses profissionais o integram desde sua implantação. Esse dado tornou-se relevante ao considerar a importância do internato de enfermagem agregar profissionais experientes e com vivência significativa com a prática, vivendo juntamente experiências sociais, políticas e pedagógicas significativas para mudanças e desafios enfrentados ao longo dos anos.

As análises das respostas às perguntas dissertativas do questionário possibilitaram formular duas categorias: Parceria entre academia e serviços de saúde: da construção a realização do internato e Avaliação do internato de enfermagem: da estruturação a efetividade.

Parceria entre academia e serviços de saúde: da construção a realização do internato de enfermagem

A primeira categoria oportunizou destacar a importância dos serviços de saúde na realização do internato de enfermagem.

Foram contempladas nessa categoria as seguintes questões: A parceria existente entre docentes e enfermeiros de campo para a construção do módulo do internato está ocorrendo de maneira efetiva? Em sua opinião é importante haver discussões entre docentes e enfermeiros de campo em relação às atividades desenvolvidas? Outras questões também foram contempladas, considerando que o tema abordado possui interfaces que se conectam nas respostas e discussões, buscando sempre o foco na parceria estabelecida entre os atores estudados.

A seguinte fala remete a construção do internato: "A edificação do internato fala por si só, sem 
a parceria enfermeiro-assistencial e docente $o$ internato não seria a realidade atual".

Ao longo dos 18 anos de existência do internato aconteceram momentos intensos de construção, avanços, desconstrução e retrocessos, etapas clássicas do trabalho coletivo. Porém, a crença que o internato somente se consolidaria calcado na parceria entre os enfermeiros, docentes, estudantes e comunidade foi sempre a prerrogativa que impulsionou este processo de formação (VANNUCHI et al., 2014).

Esse aprendizado em conjunto faz parte da complexidade do processo ensino-aprendizagem, sendo dinâmico, irregular, como uma somatória de conteúdos acrescidos aos anteriores. Tanto o docente quanto os enfermeiros de campo precisam ter ações direcionadas para que o discente aprofunde e amplie os significados elaborados mediante sua participação no campo. Com isso, todo o processo de aprendizagem é intencionalmente centrado na interação com trabalhadores da equipe de saúde e usuários, inseridos e vivenciando as dificuldades, facilidades e potencialidade do cotidiano da rede de serviços de saúde (TACLA et al., 2014).

O maior desejo dos profissionais envolvidos é que o estudante possa identificar situações favoráveis e desafiantes no campo da prática, exercendo a capacidade de reflexão sobre a ação profissional e de visão crítica sobre as relações existentes no campo institucional, apoiado na supervisão, tanto do docente quanto do enfermeiro, enquanto processo dinâmico e criativo, tendo em vista possibilitar a elaboração de novos conhecimentos (DIAS; STOLZ, 2012).

Em outra fala foi possível identificar a relevância da parceria no desenvolvimento de oficinas de trabalho, que fazem parte da construção do módulo para o planejamento anual do internato: "Anualmente antes de iniciar o internato são realizadas oficinas entre docentes e enfermeiros de campo para discutir o plano de atividades a serem desenvolvidas. Também são realizadas reuniões mensais entre os enfermeiros de campo e docentes para analisarem o desenvolvimento dos internos."
O início do internato ocorre muito antes da entrada do interno no campo de estágio, com a realização de negociações, reuniões e oficinas de trabalho com enfermeiros, coordenadores das unidades de saúde, gestores de ambas as áreas e representantes da comunidade (VANNUCHI et al., 2014).

Planejar as atividades em conjunto é compartilhar os acertos e os erros na formação do aluno e garantir que os riscos dos imprevistos ou situações que precisam de resolutividade imediata sejam enfrentados com segurança pelos profissionais envolvidos. Esses momentos têm como finalidade reafirmar entre professores e enfermeiros de serviços os objetivos do internato e as estratégias de supervisão e avaliação do processo. $O$ foco do encontro é discutir como formar enfermeiros preparados para atuar no SUS (VANNUCHI et al., 2014).

No âmbito do estágio curricular, o planejamento deve ser considerado um fator primordial para a construção de um processo de ensino-aprendizagem que corresponde às exigências de atenção à saúde da sociedade. Para tanto, o planejamento deve ter como característica a dialogicidade - valorização dos conhecimentos acadêmicos, respeito à experiência concreta advinda do mundo do trabalho e atenção às demandas dos usuários dos serviços de saúde (RODRIGUES; TAVARES, 2012).

É precisofortaleceroconceitodequeaparticipação dos enfermeiros de campo na elaboração do planejamento do estágio é indispensável e essencial, pois sua ausência nessa etapa pode revelar grandes fragilidades na construção e desenvolvimento do internato de enfermagem. Desta forma, ressaltamos que se espera do enfermeiro supervisor não apenas a sua competência técnica e experiência profissional, mas também sua competência didático-pedagógica (TAVARES et al., 2011).

O tema também envolveu relatos de dificuldades e desafios enfrentados no relacionamento dos profissionais da academia-serviço, como demonstrado nas falas seguintes: "Acredito que em 
parte. Em algumas situações o envolvimento e a parceria são excelentes, mas em outros nem sempre é assim. Depende muito dos profissionais envolvidos [...]. Alguns campos mais, outros menos. Sinto que o envolvimento do enfermeiro com a academia ainda depende do seu próprio interesse".

Essa parceria sempre se mostrou desafiadora, em função de atividades específicas de cada um dos componentes e, também, da desarticulação tradicional que há entre a academia, instituições de saúde e comunidade, sendo preciso ser alimentada permanentemente, tanto na fase de preparação de cada internato que se inicia, como durante o curso do mesmo (VANNUCHI et al., 2014).

O ambiente de trabalho apresenta diferentes categorias, e com elas, diferentes disputas de poder e espaço entre profissionais diversos e até entre a própria equipe de enfermagem. Isso emerge a necessidade de trabalhar o individualismo, a desunião e o gerenciamento do poder presente na equipe multiprofissional e na interação docenteenfermeiro-discente. Trata-se de uma questão delicada de ser abordada, tanto com profissionais como com alunos no meio teórico, por isso destacase quando é verificada por um interno que está neste ambiente há pouco tempo (LIMA et al., 2014).

Afirma-se que quanto mais possibilidades de vivenciar os diferentes espaços do cuidado, mais aumentam as possibilidades do aluno vivenciar situações que demandam ações e reflexões para melhorar seu desenvolvimento no ambiente de atuação (LIMA et al., 2014).

É possível notar que o estágio como espaço de interseção de saber-poder é pouco discutido, e muitas vezes o estudante fica alheio a todo o processo de negociação e gerenciamento de conflitos entre academia e serviço. Portanto, para que a inserção do estudante no cotidiano de trabalho dos serviços e na vida das comunidades seja produtiva e coerente, é indispensável a construção de parcerias entre universidades, serviços de saúde e comunidade, bem como a inserção do aluno em discussões e situações conflituosas tendo em vista que o mesmo irá enfrentá-las futuramente em seu ambiente de trabalho (TACLA et al., 2014).

O interno em sua imersão na prática visualiza o enfermeiro supervisor como um modelo a ser seguido na sua atuação após concluir a sua formação. Com isso, espera-se que o enfermeiro que acompanha o interno possua consciência da importância de seu papel enquanto referência profissional para o graduando e da responsabilidade de sua posição, gerando assim maior preocupação em rever e atualizar seus conhecimentos (TAVARES et al., 2011).

Referente às discussões entre docentes e enfermeiros relativas às atividades desenvolvidas relatou-se: "Com certeza é preciso falar a mesma lingua, acompanhar o desenvolvimento as potencialidades, assim como as falhas, é preciso pontuá-las para aprimorar esse momento tão rico que é o internato".

Com o início do aluno no estágio supervisionado, deve haver discussões mais profundas acerca de sua atuação e o planejamento da mesma, conciliando o que o serviço apresenta com os conteúdos teóricos trabalhados, deixando para traz paradigmas pedagógicos tradicionais e substituindo-os pela interação entre os sujeitos envolvidos neste processo. É no momento do estágio curricular que pode ocorrer uma maior interação entre ensino e serviço, em que os saberes distintos se unem de forma coerente e responsável em favor do aprendizado do aluno e do bem-estar da população (CORREIA et al., 2009).

A troca de experiência entre docente, enfermeiro e internos viabiliza o fornecimento de subsídios para preparação de todos envolvidos, como a oferta de cursos e apoio à pesquisa, instrumentos tão necessários para o aperfeiçoamento do profissional. $\mathrm{O}$ enfermeiro tanto em formação como o já atuante necessita receber um aporte teórico científico que lhe permita trabalhar o processo de assistência de enfermagem em sua concepção mais abrangente, atendendo as necessidades de saúde do indivíduo e 
comunidade de forma organizada, sistematizada e teoricamente embasada (TAVARES et al., 2011).

Foi referido que discutir as situações auxilia no tempo necessário para resolução dos problemas apresentados: "Sim, pois as dificuldades ou problemas são resolvidos em tempo real".

Os conflitos, inevitáveis no relacionamento humano, podem propiciar transformações quando são visualizados de forma positiva, pelo seu potencial de impulsionar o grupo em busca do alcance de objetivos comuns. Por isso, o relacionamento no trabalho é um processo complexo, pois cada pessoa traz consigo ligações por laços profissionais, afetivos, amizades e afinidades, sendo condicionadas por uma série de atitudes recíprocas. Consequentemente, essas características possibilitam ao trabalhador conviver com maior ou menor habilidade com seus pares nos locais de trabalho, e com isso aprimorando ou não a capacidade de gerenciar conflitos diários. Na prática profissional percebe-se que as habilidades humanas, tais como a gestão de pessoas, o gerenciamento de conflitos e capacidade de manter um ambiente de trabalho equilibrado e saudável, são importantes para a qualificação e competitividade do enfermeiro no mercado de trabalho (LIMA et al., 2014).

Afirma-se que o cenário real é sempre desafiador, assim como a prática desenvolvida pelos profissionais de saúde é sempre cercada de admiração e desafios para os estudantes. Entretanto, é preciso indagar a pertinência e abrangência das práticas adotadas a partir da problematização das experiências vividas no processo de ensino-aprendizagem, abrindo-se à construção de novos sentidos e inovações da prática (RODRIGUES; TAVARES, 2012), como mostra a fala a seguir: "Sim isto justifica a integração docente-enfermeiro e contribui para a formação do interno. O docente muitas vezes tem a argumentação cientifica que pode ser complementada com a prática do enfermeiro".

$\mathrm{O}$ internato de enfermagem ou estágio supervisionado curricular trata-se de um momento pedagógico capaz de enfrentar de maneira positiva os desafios instituídos pelas Diretrizes Curriculares para os cursos da área de saúde. Sua proposta foi idealizada para transformar as práticas de ensino, permitindo a integração entre docentes e profissionais da assistência ao receber os alunos para cumprir o estágio, numa constante busca na formação de um profissional com coerência crítica e capacidade de compreender a realidade e intervir nela, sempre trabalhando em consonância com as políticas públicas de saúde (WERNECK et al., 2010).

Existe um reconhecimento das instituições de ensino sobre a necessidade de os enfermeiros dos serviços assumirem um papel mais ativo nas políticas pedagógicas, porém são poucos os cursos onde essa participação esteja presente desde o planejamento até a avaliação, fato que ocorre na instituição do estudo (RODRIGUES; TAVARES, 2012).

No que se refere às definições das atividades a serem desenvolvidas semanalmente no campo de estágio pelos internos, todos os participantes julgaram necessário e de suma importância haver discussões entre docentes e enfermeiros. Somente o caderno do internato não garante a condução semanal do interno, é preciso que o docente esteja o número de vezes que julgar necessário durante a semana, presente no campo dialogando com o enfermeiro e o interno sobre as atividades desenvolvidas, obedecendo os desempenhos e habilidades estabelecidas para aquele momento. É um momento rico de fortalecimento da parceria com os serviços, além de estabelecer relações entre a teoria e a prática.

As falas a seguir ilustram esse momento: "São através das discussões que se pode melhorar o internato e também beneficiar o campo [...]. Só assim se podem fazer os ajustes necessários para o bom andamento do internato, para favorecer a aprendizagem dos alunos".

O princípio da comunicação visto como capacidade do ser humano inter-relacionar-se com os outros reivindica dos profissionais de enfermagem esforços para que esta seja de plena assimilação e presteza, sem rupturas ocasionadas por preconceitos 
pessoais do profissional, bem como comportamentos autoritários deste. $\mathrm{O}$ ato comunicativo, enquanto fenômeno interativo e interpretativo revela a relação necessária entre os seres humanos uma vez que é a partir do processo comunicacional que compartilhamos vivências, angústias e inseguranças ao mesmo tempo em que satisfazemos nossas necessidades enquanto seres de relação (MORAIS et al., 2009).

Portanto, é necessário que o interno desenvolva uma boa comunicação com o enfermeiro de campo e o docente que o orienta, com a equipe da unidade e com os pacientes, condição essencial para um cuidado em enfermagem que vislumbre melhor qualidade na assistência e na sua formação profissional (MORAIS et al., 2009).

A segunda categoria contemplou as formas de avaliação do internato de enfermagem.

\section{Avaliação do internato de enfermagem: da estruturação a efetividade}

Entre as questões que abordaram avaliação, estão: Em sua opinião, as normas de avaliação propostas pelo internato para supervisionar e avaliar os desempenhos dos internos estão satisfatórias? Em sua opinião, os campos de estágios estão em condições adequadas para o desenvolvimento do interno?

As seguintes falas destacam o processo avaliativo no Internato de enfermagem:

Sim. O sistema de avaliação do internato é gradual, abrange os domínios a serem desenvolvidos e permite a atuação do enfermeiro e docente [...].

Sim. Pois estão todas descritas no caderno de atividades do interno e são discutidas nas oficinas realizadas com os enfermeiros de campo.

Como uma das formas de avaliação, o interno necessita alcançar os desempenhos compatíveis com aquela fase da graduação, que representa a mobilização de suas competências relativas ao conhecimento, às habilidades e às atitudes. Com isso, a avaliação por competências utilizada durante a prática do internato visa o crescimento do aluno.

A temática da competência profissional tem se constituído foco de interesse de diversos trabalhadores de saúde, pois na formação de recursos humanos está uma possível solução das maiores questões de saúde. Espera-se que esses internos, como novos profissionais sejam capazes de interferir positivamente na modificação das condições de vida e saúde da população tomando como referência as competências profissionais a serem adquiridas, não se restringindo somente ao resultado do desempenho, porém, a partir deste, projeta-se estratégias que favorecerão o desenvolvimento das competências necessárias ao exercício do trabalho (CAMELO; ANGERAMI, 2013).

Ao avaliar o desenvolvimento ao longo do internato é perceptível que o estágio representa uma oportunidade única da formação do graduando em enfermagem. Ao mesmo tempo em que o aluno aprende, ele também ensina, e o campo de estágio em questão favorece tal vivência. Há uma nítida transformação em curso ao longo do internato de enfermagem: os alunos o iniciam de uma forma e finalizam diferentes e transformados. Sua identidade e perfil do desejado enfermeiro ideal surge, unindo a realidade e a utopia inicialmente destacada. Formase um novo profissional, a partir das experiências com os enfermeiros da unidade e as trocas de experiências com os docentes supervisores, fortalecendo a sua confiança para atuar como profissionais ao deixarem a universidade, o que parece ser a conquista maior que o estágio curricular supervisionado pode proporcionar (LIMA et al., 2014).

Referente à avaliação, destaca-se além das oficinas de preparação no início do internato, as reuniões mensais de avaliação onde os enfermeiros e docentes analisam cada campo de estágio e o desempenho do interno que ali estagia. Esta 
avaliação formativa é fundamental na condução e gestão do internato e é conduzida pelo coordenador do internato que é responsável por tomar as providências necessárias de reorganização caso haja necessidade.

O processo de avaliação está implicitamente inserido no processo de ensino e aprendizagem, que por sua vez, encontra-se fundamentado e estruturado pelo Currículo Integrado, que envolve os aspectos políticos, sociais e ideológicos do projeto pedagógico do curso. Neste sentido, a avaliação tem o compromisso com uma educação democrática, numa perspectiva de inclusão do estudante, contribuindo para que o mesmo se torne sujeito de sua aprendizagem e enfatizando o processo educativo e o resultado qualitativo do aprendizado. Do ponto de vista crítico, a avaliação deve ter um caráter formativo, ou seja, deve ser contínua e contribuir para a progressão, para o desenvolvimento ou a melhoria da aprendizagem em curso (KIKUCHI et al., 2014).

Ao final do ano, realiza-se uma grande reunião de encerramento, momento em que há possibilidade de pronunciamentos dos enfermeiros de campo, docentes e alunos. Para esta reunião de encerramento, são convidadas autoridades que representam as instituições onde ocorre o internato além de lideranças comunitárias. Este momento é considerado de avaliação final, mas também de uma grande celebração.

Os campos de estágios também são avaliados para receberem os internos, sendo de suma importância que proporcionem além de estrutura física adequada, um ambiente real do sistema de saúde que o interno, futuro profissional irá enfrentar no seu processo de trabalho.

Quando questionados sobre o preparo do campo para iniciar o internato referiram a importância de oferecer aos internos subsídios como instruções do funcionamento da planta física, perfil dos pacientes, conhecimento da equipe de funcionários, entre outros para facilitar sua atuação durante o estágio, pois o mesmo sente-se inserido no processo de trabalho, o que o auxiliará a buscar mais rapidamente a sua autonomia, como ilustra a fala abaixo: "Sim, é preciso aproximar o sujeito da sua área de trabalho, fazê-lo entender em pouco tempo como tudo funciona".

$\mathrm{O}$ enfermeiro de campo em parceria com o docente supervisor tem papel fundamental para orientar o interno no desenvolvimento das atividades práticas de acordo com o plano preestabelecido e com a infraestrutura de cada unidade de estágio. $\mathrm{O}$ docente acompanha o interno durante o processo de inserção do aluno na unidade de estágio propiciando segurança tanto para o interno quanto para a equipe que o recebe em todo o desenvolvimento do aprendizado do processo de trabalho da unidade.

Ressalta-se que o interno não constrói conhecimentos somente por intermédio dos estudos acadêmicos, mas no dia a dia, com apoio nos desafios da realidade de seu trabalho e dos profissionais envolvidos. A teoria oferece o que pode ser apreendido e compreendido por todos, enquanto a prática, o trabalho e sua complexidade proporcionam aprendizagem mais rica e produtiva em termos de significado para o aluno em campo. $\mathrm{O}$ trabalho representa o elo entre pensamento e prática, expressando a capacidade humana de reelaborar a realidade pela ação, podendo recriá-la e modifica-la (NÓBREGA-THERRIEN et al., 2010).

Sabe-se que o atendimento as diversidades dos problemas de saúde exigem do profissional e também do aluno em formação variadas ferramentas de trabalho, envolvendo tecnologias e saberes que precisam ser adquiridos ainda durante a formação acadêmica, como exemplificada na fala acima referente aos conhecimentos do seu local de trabalho e das necessidades apresentadas de acordo com o perfil dos pacientes (COSTA; MIRANDA, 2010).

Esses diferentes meios e instrumentos de trabalho indispensáveis qualificam e aprimoram a prestação da atenção integral e humanizada às 
pessoas. A formação que adota a perspectiva da contextualização e da escuta das necessidades de saúde também assegura ao aluno a capacidade de problematizar e de descobrir as soluções criativas e cooperativas para os problemas reais, permitindo a construção do saber e da autonomia, com a intervenção do profissional de saúde na reorientação do modelo assistencial (COSTA; MIRANDA, 2010).

Porém as diversidades de opiniões que enriquecem o processo do internato também surgiram nessa questão, pois alguns entrevistados consideraram que a partir do momento que o aluno está inserido em seu campo de estágio o mesmo deve buscar o conhecimento no desenvolver da prática diária. "Acho que não pois eles se apropriam do serviço no dia a dia [...]. Acho que o aluno já tem esse subsidio durante as atividades práticas desenvolvidas nos anos anteriores".

Constantemente discutem-se até onde o docente e o enfermeiro devem interferir na prática dos internos de enfermagem por se priorizar a autonomia como um dos atributos alcançados com o desenvolvimento do aluno. A formação do enfermeiro deve estar voltada ao desenvolvimento de competências e habilidades gerais que abrangem atenção à saúde, tomada de decisão, comunicação, trabalho em equipe, liderança, administração/ gerenciamento e a educação permanente.

A equipe de saúde onde o interno está atuando questiona a sua autoridade, quando este ocupa espaços de gerenciamento e de problematização do cuidado realizado. Essa relação gera vínculo entre aluno e equipe, com respeito, cooperação em que a ajuda mútua garante uma experiência de atuação em equipe (VANNCHI et al., 2014).

Todos desejam que os internos correspondam às necessidades da equipe e sejam comprometidos, saibam os procedimentos técnicos corretos, gostem da área e se envolvam com as situações que consideram importantes. Porém é preciso respeitar as diferenças, uma vez que cada aluno possui um tempo de desenvolvimento, podendo não corresponder às expectativas criadas, pois estão em processo de formação e precisam ser expostos a situações que propiciem reflexão das vivências (VANNCHI et al., 2014).

Referente às estruturas físicas, os profissionais responderam que as unidades de estágios oferecem características positivas aos internos, no sentido de oportunizar a eles vivenciarem situações reais da prática cotidiana do enfermeiro. "São cenários reais que possibilitam o desenvolvimento de competências assistenciais, de gerência e de ensino [...]".

"É nestes locais que o trabalho acontece. É a realidade. Os enfermeiros devem ser formados para a realidade que vão encontrar".

As condições de trabalho contribuem sobremaneira para determinar o processo de saúdedoença dos trabalhadores de enfermagem. É muito rico para o interno perceber que os determinantes da saúde do trabalhador compreendem os condicionantes sociais, econômicos, tecnológicos e organizacionais responsáveis pelas condições de vida e os fatores de risco ocupacionais que estão presentes nos processos de trabalho (MAURO, 2010).

O Internato dá a possibilidade ao aluno de entender e vivenciar o contexto social, político e econômico que interfere na estrutura da organização, na regulação das relações de trabalho e nas políticas de recursos humanos. A presença do interno em diferentes unidades permite mostrar a eles que as instituições de saúde são modelos complexos de gerenciamento, que exigem adequação tanto em aspectos físicos como humanos para proporcionar um ambiente adequado aos trabalhadores (MAURO, 2010).

Os cursos de graduação em enfermagem devem buscar constantemente na formação de seus estudantes a aplicação de um currículo que atenda às necessidades de saúde da população no SUS, bem como as exigências do mercado de trabalho atual. É preciso conectar o objetivo da 
proposta pedagógica com a empregabilidade e desenvolvimento de práticas efetivas que atendam as demandas da comunidade. Para isso é preciso que as coordenações dos cursos, assim como na instituição destacada no estudo invistam ativamente em atenção à saúde e formação de enfermeiros, com visão crítica e reflexiva, visando, sobretudo, atender as diretrizes e princípios estabelecidos pelo SUS (REZENDE et al., 2014).

Por fim, destaca-se que o processo de avaliação ocorre durante todo o desenvolvimento do internato de enfermagem, seja ao avaliar as estruturas físicas envolvidas na prática, como as relações interpessoais entre docente, enfermeiro de campo, interno e equipe de trabalho, além dos métodos e instrumentos utilizados para que a práxis ocorra, potencializando assim a avaliação como ferramenta gerencial essencial no desenvolvimento do processo de trabalho dos enfermeiros.

\section{Conclusão}

O curso de enfermagem da Universidade Estadual de Londrina em seus 40 anos de existência sempre primou pelos aspectos pedagógicos relacionando-os a uma formação com qualificação humana, plena, crítica e competente. Nesse sentido, o internato de enfermagem, que representa os estágios curriculares, só conseguiu esta qualificação preconizada pelo curso devido a aproximação com os enfermeiros dos serviços de saúde e o apoio das instituições de saúde onde ocorrem os estágios, tanto na área hospitalar como na saúde coletiva.

Os depoimentos dos enfermeiros docentes e enfermeiros de campo foram objetos de transformação do movimento de pensar da prática do internato de enfermagem e a integração eficaz e ativa entre os participantes do internato, ou seja, estudantes, docentes e os enfermeiros assistenciais prova a efetividade na condução deste momento na formação do enfermeiro, propiciando aos alunos contato direto com a realidade dos serviços de saúde sob orientação dos enfermeiros de campo e supervisão dos docentes.

Há que se ressaltar nesta parceria o apoio incondicional das instituições de saúde oportunizando maior embasamento político e pedagógico para a realização da prática, abrindo oportunidades de crescimento do internato e do conhecimento oferecido aos estudantes, voltado para as necessidades do SUS.

A apresentação da realidade do sistema pelas instituições de saúde demonstra que as fragilidades e potencialidades encontradas contribuem para a formação do aluno que se depara com a veracidade, servindo de estímulo para o aprendizado e amadurecimento dos estudantes.

Apesar das limitações deste estudo no que se refere ao baixo retorno dos enfermeiros e docentes em responder ao questionário eletrônico, ficou evidente tanto a importância das instituições de saúde e de seus profissionais na formação da dimensão da gestão e da prática e pedagógica do internato de enfermagem.

Há um compartilhamento frequente em todas as etapas necessárias para o planejamento e consolidação anual de cada internato o que faz cada vez mais esta parceria ativa entre a academia, o curso de Enfermagem da UEL e os serviços de saúde envolvidos na formação dos enfermeiros que o SUS tanto necessita.

A parceria consolidada ao longo dos anos é irreversível, no entanto, há que sempre aprimorála e solidificá-la, pois ainda tem-se muito mais a avançar em busca da formação de um profissional preparado para assumir as responsabilidades dos serviços de saúde no Brasil.

\section{Referências}

BARDIN, L. Análise de conteúdo. 3. ed. Lisboa: Edições 70, 2009. 
BARROSO, M.; COUTINHO, C. Google Docs: uma experiência de trabalho cooperativo com alunos do $8^{\circ}$ ano de escolaridade. Revista PRISMA.COM., Porto, n. 8, 2009. Disponível em: <http://revistas.ua.pt/index.php/prismacom/ article/view/689>. Acesso em: 18 dez. 2014.

CAMElO, S. H. H.; ANGERAMI, E. L. S. Competência profissional: a construção de conceitos, estratégias desenvolvidas pelos serviços de saúde e implicações para a enfermagem. Texto \& Contexto EM Enfermagem, Florianópolis, v. 22, n. 2, p. 552-560, 2013.

COLENCI, R.; BERTI, H. W. Professional development and entering the labor market: the perceptions of nursing graduates. Revista da Escola de Enfermagem da USP, São Paulo, v. 46. n. 1, p. 158-166, 2012.

CORREIA, A. L.; SILVA, C. C.; SILVA, A. T. M.; BRAGA, J. E. P. Necessidades dos serviços e exigências da academia: uma articulação possível. Revista Brasileira de Ciências da Saúde, São Caetano do Sul, v. 13, n. 1, p. 7-12, 2009.

COSTA, L. M.; GERMANO, R. M. Estágio curricular supervisionado na graduação em enfermagem: revisitando a história. Revista Brasileira de Enfermagem, Brasília, v. 60, n. 6, p. 706-710, 2007.

COSTA, R. K. S.; MIRANDA, F. A. N. Formação profissional no SUS: oportunidades de mudanças na perspectiva da estratégia de saúde da família. Trabalho, Educação e Saúde, Rio de Janeiro, v. 6, n. 3, p. 503-517, 2009.

COSTA, R. K. S.; MIRANDA, F. A. N. Opinião do graduando de enfermagem sobre a formação do enfermeiro para o SUS: uma análise da FAEN/UERN. Escola Anna Nery Revista de Enfermagem, Rio de Janeiro, v. 14, n. 1, p. 39-47, 2010 .

DAVID, H. M. S. L.; ACIOLI, S. Mudanças na formação e no trabalho de enfermagem: uma perspectiva da educação popular e de saúde. Revista Brasileira Enfermagem, Brasília, v. 63, n. 1, p. 127-131, 2010.
DEMARZO, M. M. P.; ANDERSON, M. I. P.; SILVEIRA, L.; HADDAD, A. E, MARINS, J. J. N, SILVA, M. R. E. Diretrizes para a integração ensino-serviço-comunidade na formação em atenção primária a saúde e medicina de família e comunidade. Revista da APS, Juiz de Fora, v. 12, n. 2, p. 228-229, 2009.

DIAS, D. G.; STOLZ, P. V. Projeto de extensão vivências para acadêmicos de enfermagem no Sistema Único de Saúde na perspectiva do acadêmico. Journal of Nursing and Health, Pelotas, v. 2, n. 2, 440-445, 2012.

INOCENTE, D. F, SCORSOLINI-COMIN, F.; MATIAS, A. B. A qualidade de vida de alunos de cursos de pós-graduação na modalidade a distância: conjugando educação, trabalho e saúde. In: JESUS, S. N.; LEAL, I.; REZENDE, M. (Org.). Experiências e intervenções em psicologia da saúde. Faro: Universidade do Algarve, 2009. p. 445-462.

KIKUCHI, E. M.; ROSSETO, E. G.; LOPES, D. F. M.; TOMELERI, K.; FERRARI, R. A. P, HIRAZAWA, S. A. Avaliação da aprendizagem no currículo integrado. In: KIKUCHI, E. M.; GUARIENTE, M. H. D. M. (Org.). Currículo integrado: a experiência do curso de enfermagem da Universidade Estadual de Londrina. Londrina: UEL, 2014. p. 129-145.

LIMA, T. C.; PAIXÃO, F. R. C., CANDIDO, E. C.; CAMPOS, C. J. G.; CEOLIM, M. F. Estágio curricular supervisionado: análise da experiência discente. Revista Brasileira de Enfermagem, Brasília, v. 67, n. 1, p.133-140, 2014.

MATTOSINHO, M. M. S.; COELHO, M. S.; MEIRELLES, B. H. S.; SOUZA, S. S. ARGENTA, C. E. The world of work: some aspects experienced by professional nurses recently. Acta Paulista de Enfermagem, São Paulo, v. 23, n. 4, p. 466-471, 2010.

MAURO, M. Y. C. Condições de trabalho da enfermagem nas enfermarias de um hospital universitário. Escola Anna Nery Revista de Enfermagem, Rio de Janeiro, v. 14, n. 1, p. 13-18, 2010 . 
MORAIS, G. S. N.; COSTA, S. F. G.; FONTES, W. D, CARNEIRO, A. D. Communication as a basic instrument in providing humanized nursing care for the hospitalized patient. Acta Paulista Enfermagem, São Paulo, v. 22, n. 3, p. 323-237, 2009.

NÓBREGA-THERRIEN, S. M.; GUERREIRO, M. G. S.; MOREIRA, T. M. M.; ALMEIDA, M. I. Projeto político pedagógico: concepção, construção e avaliação na enfermagem. Revista Escola Enfermagem da USP, São Paulo, v. 44, n. 3, p. 679-686, 2010 .

POPE, C.; MAYS, N.(Org.). Pesquisa qualitativa na atenção à saúde. 3. ed. Porto Alegre: Artmed, 2009.

REZENDE, R. C. B.; OLIVEIRA, M. M. B.; ALVES, E.; CESTAR, E. W. Projetos que potencializam a formação do graduando de enfermagem.In:KIKUCHI, E. M.; GUARIENTE, M. H. D. M. (Org.). Currículo integrado: a experiência do curso de enfermagem da Universidade Estadual de Londrina. Londrina: UEL, 2014. p.195-206.

RODRIGUES, L. M. S, TAVARES, C. M. M. Estágio supervisionado de enfermagem na atenção básica: o planejamento dialógico como dispositivo do processo ensino-aprendizagem. Revista Rene: Revista da Rede de Enfermagem do Nordeste, Fortaleza, v. 13, n. 5, p. 1075-1083, 2012.

TACLA, M. T. G. M.; ZANI, A. V.; ROSSETTO, E. G.; PIERI, F. M.; CESTARI, M. E. W. Boas práticas de ensino no currículo integrado de enfermagem. In: KIKUCHI, E. M.; GUARIENTE, M. H. D. M, (Org.). Currículo integrado: a experiência do curso de enfermagem da Universidade Estadual de Londrina. Londrina: UEL, 2014. p. 75-92.

TAVARES, P. E. N.; SANTOS, S. A. M.; COMASSETTO, I.; SANTOS, R. M.; SANTANA, V. V. R. S. A vivência do ser enfermeiro e preceptor em um hospital escola: olhar fenomenológico. Revista RENE, Fortaleza, v. 12 , n. 4 , p. 798-807, 2011.
VANNUCHI, M. T. O.; LIMA, J. V. C.; SILVA, L. G. C.; CARDOSO, M. G. P.; DELLAROZA, M. S. G.; HADDAD, M. C. F. L. O internato de enfermagem no currículo integrado. In: KIKUCHI, E. M.; GUARIENTE, M. H. D. M. (Org.). Currículo integrado: a experiência do curso de enfermagem da Universidade Estadual de Londrina. Londrina: UEL, 2014. p. 177-192.

WERNECK, M. A. F.; SENNA, M. I. B.; DRUMOND, M. M.; LUCAS, D. S. Nem tudo é estágio: contribuições para o debate. Ciência e Saúde Coletiva, Rio de Janeiro, v. 15, n. 1, p. 221-231, 2010.
Recebido em: 23 jul. 2014. Aceito em: 09 mar. 2015. 
